\title{
Extending the Operating Range of Electric Spring Using Back-To-Back Converter: Hardware Implementation and Control
}

\author{
Shuo Yan, Student Member, IEEE, Chi-Kwan Lee, Senior Member, IEEE, Tian-bo Yang, Student \\ Member, IEEE, K. T. Mok, Student Member, IEEE, Siew-Chong Tan, Senior Member, IEEE, Balarko \\ Chaudhuri Senior Member, IEEE, and S. Y. Ron Hui, Fellow, IEEE
}

\begin{abstract}
This paper presents the first hardware implementation and control of an electric spring based on a back-to-back converter configuration. Because of its ability to provide both active and reactive power compensation, this back-to-back electric spring (ES-B2B) can substantially extend the operating range of the original version of the electric spring (ES-1) and provide enhanced voltage support and suppression functions. The hardware system and control of the ES-B2B have been successfully developed and tested. The experimental results have confirmed the effectiveness of the ES-B2B in supporting and suppressing the mains voltage. Particularly, the voltage suppression ability of the ES-B2B is superior over that of ES-1. The use of ES-B2B in a simulation study of a weak power grid has also been conducted. The ES-B2B has been found to be highly effective in mitigating voltage fluctuation caused by intermittent renewable power generation.
\end{abstract}

Index Terms-electric springs, back-to-back converters, smart grids, smart loads, adaptive systems.

\section{INTRODUCTION}

$\mathrm{T}_{\mathrm{p}}^{\mathrm{h}}$ he increasing use of intermittent renewable energy has posted new challenge to the power grid [1], [2]. The intermittent generation profile of renewable energy makes it difficult to maintain the supply-to-demand balance in real time. Traditional demand-side management approaches involve load shaving, day-ahead and hour-ahead forecasts, on/off control of noncritical loads, and pricing policies [3]-[9]. As a demand-response technology with response time in the order of milliseconds, electric springs have recently been proposed for providing future power grid with a range of attractive feature such as mitigation of voltage and frequency fluctuations [10][13], reduction of energy storage requirements [14], reduction of power imbalance in buildings [15], [16]. So far, three

Manuscript received January 30 2016; revised May 18 2016; accepted August 28 2016. This work was supported by the Hong Kong Research Council under Grant: T23-701/14-N.

Shuo Yan, Chi-Kwan Lee, Tian-bo Yang, K. T. Mok, and Siew-Chong Tan are with the Department of Electrical \& Electronic Engineering, The University of Hong Kong (e-mail: yanshuo@connect.hku.hk).

B. Chaudhuri is with the Department of Electrical \& Electronic Engineering, Imperial College London (e-mail: b.chaudhuri@imperial.ac.uk).

S.Y.R. Hui is with Department of Electrical \& Electronic Engineering, The University of Hong Kong (e-mail: ronhui@eee.hku.hk) and also with Imperial College London (e-mail: r.hui@imperial.ac.uk).

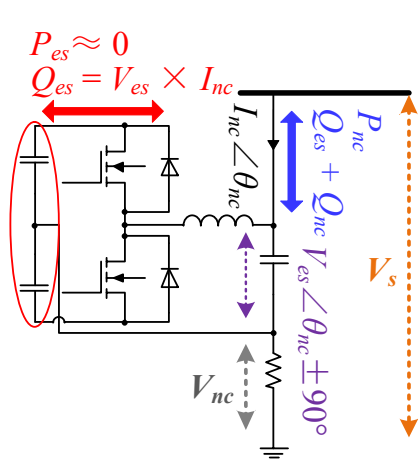

(a)

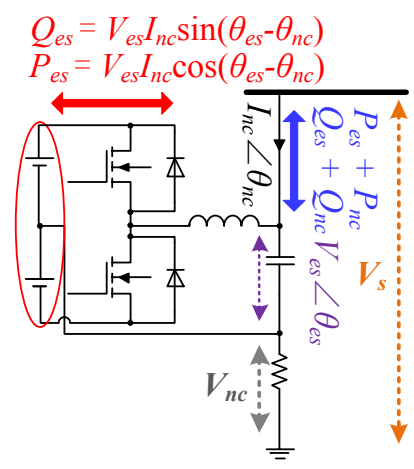

(b)

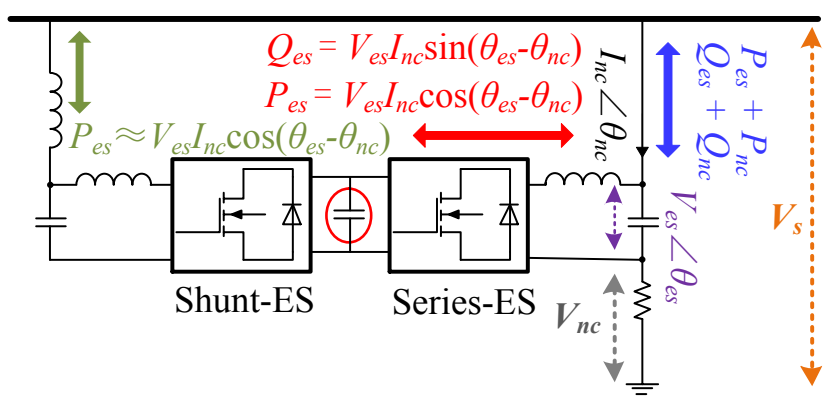

(c)

Fig. 1. Schematics of electric springs. (a) Electric spring version-1 (ES-1). (b) Electric spring version-2A (ES-2). (c) Electric spring version-2B (ES-B2B). versions of ES have been suggested. The original version (ES-1) involves a power inverter with a DC storage capacitor [10] as shown in Fig. 1(a). It is connected in series with a noncritical load. It provides direct reactive power compensation through the generation of a voltage in series with the noncritical load and indirect active power compensation through the modulation of the noncritical load power. The second version of ES (ES-2) is also connected in series with a noncritical load and consists of an active energy storage (such as a battery [17]) as illustrated in Fig. 1(b). Unlike ES-1, ES-2 provides both direct active and reactive power compensation and therefore has a much wider range. ES-1 has better voltage-supporting function than voltage-suppressing function. This problem can be readily solved by using ES-2 at the expense of the requirement for a battery (that has maintenance and cost issues). While the ES-2 can be embedded in a noncritical load, a preferred option is to install it as part of the power supply 


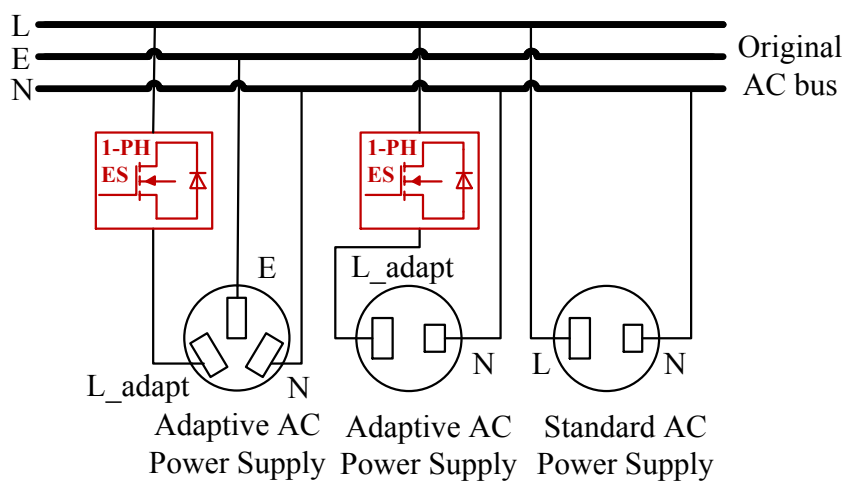

Fig. 2. Proposed new mains infrastructure for the future power grid.

infrastructure as shown in Fig. 2. In this new infrastructure for future power grid, the regulated mains can be considered as a standard mains, and the output of the ES can be treated as a new adaptive mains. Consumers using this adaptive mains with noncritical loads will be helping the utilities to stabilize the power grid with intermittent power sources. In this paper, the ES concept is explored with the practical use of a back-to-back converter configuration as shown in Fig. 1(c). It has the advantages of not using any battery because the DC voltage of the $\mathrm{DC}-\mathrm{AC}$ power converter is provided by an AC-DC power converter. The operating principle of this ES-B2B will be explained and practically verified with an experimental prototype.

\section{TOPOLOGY OF THE ES-B2B}

This section explains the topology of ES-B2B and its benefits over other counterparts. Typical topologies of existing ESs include half-bridge inverter [10], full bridge inverter [16], and three-phase inverter [15]. Either capacitor [10] or battery [17] has been used as energy storage. The first version of ES with capacitor (ES-1) has the advantage of simple implementation but shows a few operating limitations. As stated in [10], the output voltage of ES-1 is continuously modulated to be perpendicular with the noncritical load current. This control restriction limits the ES-1 in modulating the active power. Consequently, the ES-1 has good voltage supporting function and limited voltage suppression function. The ES proposed in [17] uses battery as energy storage (ES-2). Battery storage on the DC link allows the ES-2 to exchange active and reactive power with the grid. Therefore, the ES-2 voltage vector is no longer restricted to be perpendicular with the noncritical load current vector but can be set in any arbitrary angle. This version of ES has been used to conduct tasks such as voltage stabilization [13], power balance [15], [16], and power quality improvement [18].

The new ES-B2B consists of two half-bridge inverters configured in a back-to-back structure (Fig. 3). One of the half-bridge inverter is used to be series compensator (Series-ES), and the other one to be a shunt compensator (Shunt-ES). The common DC link provides a channel for two-way power flow between Series-ES and Shunt-ES. The Series-ES possesses the operating modes of ES-2. The Shunt-ES is designated to cooperate with Series-ES by maintaining a stable voltage on the DC link. In addition, it can

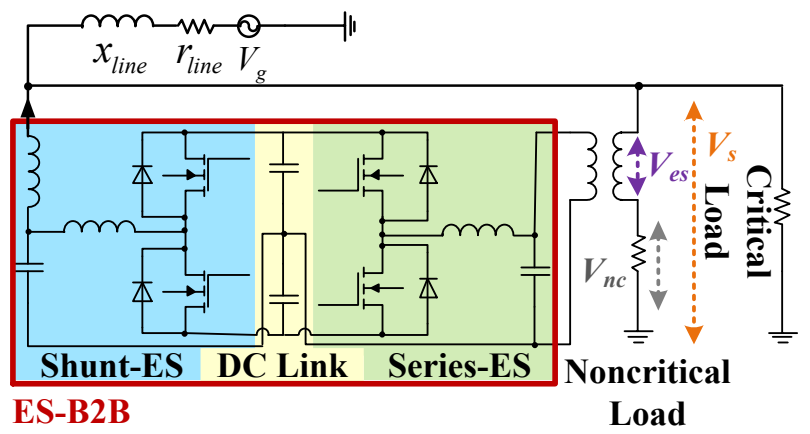

Fig. 3. Circuit diagram of the ES-B2B.

provide extra tasks such as reactive power compensation and harmonics cancellation.

An isolation transformer is connected on the output of the Series-ES to decouple the neutral point of Series-ES and Shunt-ES. The secondary side of the isolation transformer is connected in series with the noncritical load to couple the compensation voltage into the system. This implementation inherits the function of the ES-2 that the bouncing effect of the compensation voltage can actively change the power consumption of the noncritical load. The output of the Shunt-ES is connected to the mains via an inductor.

The configuration of a bidirectional inverter as ES-B2B is different from a unified power flow controller (UPFC). The Series-ES adopts an input control to regulate the mains voltage $\left(\boldsymbol{V}_{\boldsymbol{s}}\right)$ and provides an adaptive mains voltage $\left(\boldsymbol{V}_{\boldsymbol{n}}\right)$ for the noncritical load (Fig. 3). The series combination of the Series-ES and the noncritical load makes it possible to modulate the power of the noncritical load in order to balance supply and demand. Consequently, the noncritical load fed by the adaptive voltage output of the ES automatically becomes an adaptive load. Such adaptive (or smart) load can be regarded as a fast demand-response technology for the power grid. If those adaptive loads are distributed on the distribution network of the power grid, they form a robust stability support for the power grid.

\section{Operating PrinciPles OF THE ES-B2B}

\section{A. Operating modes of the ES-B2B}

With Shunt-ES providing another channel of power flow, the ES-B2B possesses a highly effective ability to support and suppress the mains voltage. The vector diagrams of the simplified power grid with and without the support of the ES are shown in Fig. 4 and Fig. 5 for voltage support mode and voltage suppression mode respectively. For the ease of analysis, the noncritical load is assumed to be resistive, although it is not a necessary condition [17].

\section{1) Voltage support mode}

The ES will be operated under voltage support mode when the mains voltage falls below its nominal value. Before the ES-B2B is activated, both the noncritical load and the critical load are supplied with the mains voltage $\left(\boldsymbol{V}_{\boldsymbol{s}}\right)$ lower than its normal voltage $\left(\boldsymbol{V}_{\boldsymbol{s}_{-} \text {nom }}\right)$, as shown in Fig. 4(a). When ES-B2B is activated, a compensation voltage ( $\left.\boldsymbol{V}_{\text {series-ES }}\right)$ in phase with the mains voltage $\left(\boldsymbol{V}_{\boldsymbol{s}}\right)$ can be introduced. This compensation 


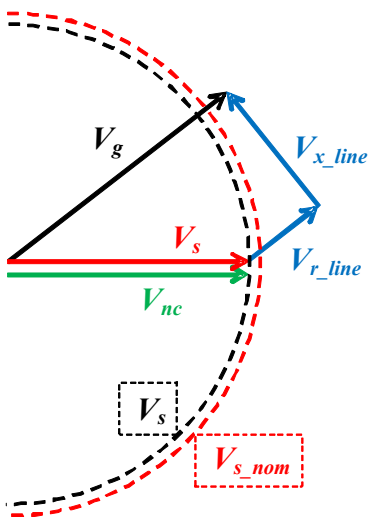

(a)

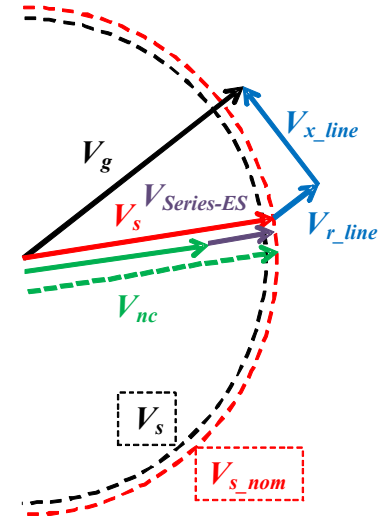

(b)
Fig. 4. Vector diagram of ES-B2B when supporting voltage. (a) Without ES. (b) With ES.

voltage ( $\left.\boldsymbol{V}_{\text {series-ES }}\right)$ suppresses the voltage of noncritical load $\left(\boldsymbol{V}_{\boldsymbol{n} \boldsymbol{c}}\right)$ and thus reduces its power. The consequential reduction in line current results in the reduced voltage drop on the distribution line. The mains voltage can thus be supported up to its nominal value as shown in Fig. 4(b). The vector relationship between Series-ES voltage ( $\left.\boldsymbol{V}_{\text {series-ES }}\right)$ and the noncritical load voltage $\left(\boldsymbol{V}_{\boldsymbol{n}}\right)$ shows that the Series-ES operating in resistive mode absorbs active power from the grid and stores it in DC link. Due to the limited storage capacity, the Shunt-ES needs to deliver the absorbed power from the DC link back into the grid so that the capacitors would not be over charged and the DC voltage can remain constant. A power circulation is thus established in a way that the active power absorbed by Series-ES is continuously fed back into the grid by Shunt-ES and reused by Series-ES. This power circulation can effectively reduce the power consumption of Series-ES operating in resistive mode. As compared with the ES-2 with battery, ES-B2B shows an enhanced ability to support voltage. When being activated to support the mains voltage, the ES-2 is operated in resistive mode and consumes active power. With no feedback channel, the absorbed energy has to be stored in the batteries. If this operation prolongs, a large battery capacity is required. In addition, the active power consumed by ES- 2 could compromise the power reduction of the noncritical load intended for voltage support. Consequently, the voltage support function of the ES-2 is partially sacrificed by the resistive mode of the ES-2. With the power circulation made possible by Shunt-ES, this contradiction inherent in the ES-2 can be avoided by the ES-B2B topology.

\section{2) Voltage suppression mode}

When the mains voltage is higher than its nominal value, the vector diagrams without and with the ES-B2B are shown in Fig. 5(a) and Fig. 5(b), respectively. When the ES-B2B is activated, an compensation voltage ( $\boldsymbol{V}_{\text {series-ES }}$ ) out of phase with the mains voltage $\left(\boldsymbol{V}_{\boldsymbol{s}}\right)$ is generated to boost the noncritical load voltage $\left(\boldsymbol{V}_{\boldsymbol{n}}\right)$, as shown in Fig. 5(b). The original noncritical load voltage (highlighted in dotted green vector) is placed beside the compensated one. The introduction of ES voltage ( $\left.\boldsymbol{V}_{\text {series-ES }}\right)$ causes power consumption of the noncritical load to increase, which increases the voltage drop on distribution line. The mains voltage $\left(\boldsymbol{V}_{\boldsymbol{s}}\right)$ is thus suppressed. The corresponding vector relationship between the Series-ES voltage ( $\left.\boldsymbol{V}_{\text {series-ES }}\right)$

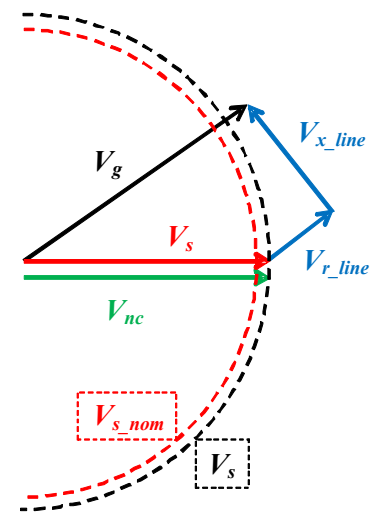

(a)

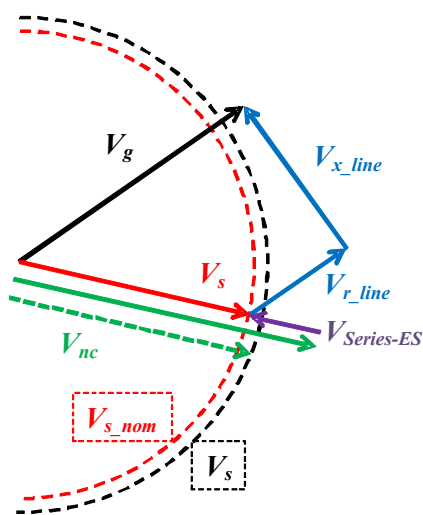

(b)
Fig. 5. Vector diagram of ES-B2B when suppressing voltage. (a) Without ES. (b) With ES.

TABLE I

SPECIFICATIONS OF THE EXAMPLE FOR ES OPERATING RANGE

\begin{tabular}{cc}
\hline \hline Symbol & Value \\
\hline$V_{s}$ nominal value & $220 \mathrm{~V}(\mathrm{RMS})$ \\
Nominal power & $2 \mathrm{kVA}, P F=0.85$ \\
$V_{\text {series-ES }}(\mathrm{RMS})$ & $0.68 p . u$. \\
Power rating of Series-ES & $0.50 p . u$. \\
Voltage rating of Shunt-ES & $1.00 p . u$. \\
Power rating of Shunt-ES & $0.50 p . u$. \\
Noncritical load nominal power & $0.55 p . u$. (resistive) \\
Critical load nominal power & $0.33 p . u ., P F=0.80$ \\
\hline \hline
\end{tabular}

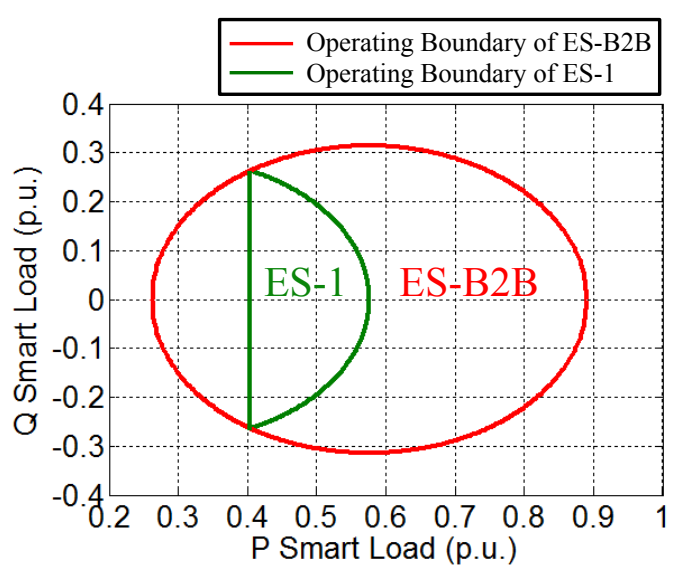

Fig. 6. Operating ranges of ES-B2B and the ES-1.

and noncritical load voltage $\left(\boldsymbol{V}_{\boldsymbol{n} \boldsymbol{c}}\right)$ indicates that Series-ES is operated in negative-resistive mode when suppressing the mains voltage. When operating in negative-resisitve mode, Series-ES supplies active power to the noncritical load. The Shunt-ES draws this active power from grid and delivers it to Series-ES via the DC link. The power transfered by the Shunt-ES increases the loading current and further reduces the mains voltage (due to the enlarged voltage drop on the distribution line).

\section{B. Operating Range and Limit of the ES-B2B}

Similar to mechanical spring that cannot extend and retract infinitely, the ES-B2B must operate within its practical limits. 
The shunt structure and half-bridge circuit of Shunt-ES require that the DC voltage must be comparable to the voltage level of intended power grid. Once the DC voltage is stabilized, the Series-ES can generate compensation voltage to vary the power of the noncritical load. The stabilization of DC voltage requires that an active current must be exchanged between the Shunt-ES and the mains. The operating boundary of the ES-B2B can be determined with given ratings of the Shunt-ES and the Series-ES. The specifications of an example are tabulated in TALBE I. The oval area in Fig. 6 shows the compensation capacity of the ES-B2B, and the D-shaped area is that of the ES-1. It is clear that the ES-B2B can greatly expand the operating range of the ES.

\section{CONTROL OF THE ES-B2B}

The control of ES-B2B needs to achieve a few targets: (i) the maintenance of a stable DC voltage, (ii) the balanced power flow between Series-ES and Shunt-ES, and (iii) the extended voltage regulation function. The scheme introduced in [19] uses the mathematic model of ES-B2B and consider ES-B2B as a self-regulated entity, so the inner power flow between Series-ES and Shunt-ES is not considered in the control loop. In hardware implementation, the cooperation of Series-ES and Shunt-ES is essential in the operation of ES-B2B. Following those considerations, a detailed control scheme is discussed in this section.

For mains voltage regulation, the Series-ES can generate compensation voltage either in phase or out of phase with the mains voltage to adapt the power consumption of its associated noncritical load. Meanwhile, the Shunt-ES cooperates with Series-ES to stabilize the DC voltage and maintain a balanced power flow. Specifically, the negative-resistive mode (needed for the Series-ES to suppress the mains voltage) requires the Series-ES to release active power and Shunt-ES to acquire this active power from the grid. The resistive mode (needed for Series-ES to support the mains voltage) requires the Series-ES to absorb active power and the Shunt-ES to inject this active power back to grid.

To separate the control of active and reactive power of ES-B2B, the controller is developed in a decoupled single-phase $d-q$ framework where the mains voltage is chosen to be the reference vector with a phase angle of $0^{\circ}$. Equations (1) and (2) give the mathematic expressions of the single-phase polar to $d-q$ transformation. Mains voltage $\left(\boldsymbol{V}_{\boldsymbol{s}}\right)$, critical load voltage $\left(\boldsymbol{V}_{\boldsymbol{n}}\right)$, and the current of Shunt-ES (I $\left.\boldsymbol{I}_{\text {shunt-ES }}\right)$ are transformed into their respective $d$ and $q$ components in the control scheme.

$$
\begin{aligned}
& d=A \cos \theta=\frac{2}{T} \int_{T_{n}}^{T_{n+1}} A \sin (\omega t+\theta) \sin (\omega t) d t \\
& q=A \sin \theta=\frac{2}{T} \int_{T_{n}}^{T_{n+1}} A \sin (\omega t+\theta) \cos (\omega t) d t
\end{aligned}
$$

In (1) and (2), the symbol $A$ refers to the amplitude of currents or voltages, $\omega$ is the fundamental angular frequency at which all decoupled $d$ and $q$ components are rotating, $\theta$ is the angle of currents or voltages with respect to the reference vector whose phase angle is tracked to zero degree by the phase-locked-loop (PLL).

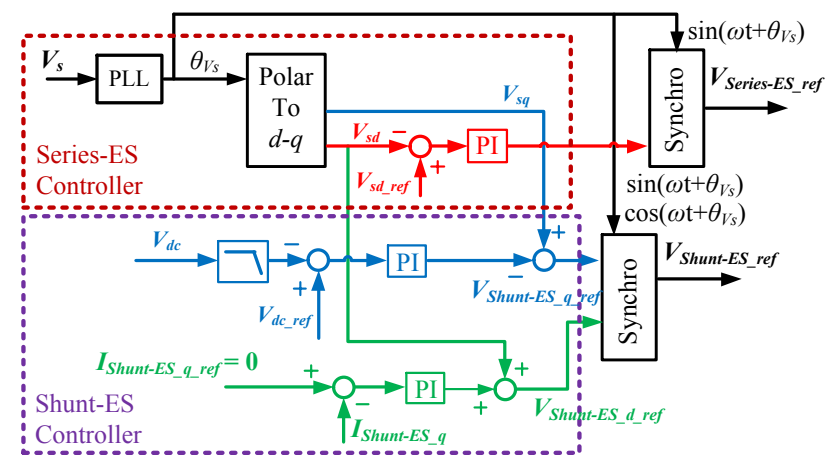

Fig. 7. Proposed control loop of ES-B2B.

The implementation of single-phase $d-q$ transformation can facilitate the decoupling of active and reactive power control of the ES-B2B and thus simplify the control structure. Specifically, active power flow of the ES-B2B can be directly controlled by modulating the $d$ component of Series-ES voltage $\left(V_{\text {series-ES_l } d}\right)$ and the $q$ component of Shunt-ES voltage $\left(V_{\text {shunt-ES } q}\right)$. The reactive power capacity of the ES-B2B can be applied to perform additional functions such as power factor correction and harmonic reduction, if necessary.

Fig. 7 shows the control diagram of the ES-B2B, in which three control loops are highlighted respectively in red, blue, and green colors. The control loop highlighted in red color is designated to operate the Series-ES for mains voltage support and suppression. This control loop follows the technique proposed in [20] that the Series-ES increases or decreases the supply voltage of the noncritical load while keeping its phase angle unchanged. Equation (3) is the mathematical expression of the voltage reference of the Series-ES. The $d$ component of the mains voltage $\boldsymbol{V}_{\boldsymbol{s}}\left(V_{s d}\right)$ is fed back and compared with $V_{s_{-} r e f}$ (the nominal value of the mains voltage in a targeted power grid). The error signal is fed to a PI controller, which generates the $d$ component of the Series-ES reference $\left(V_{\text {series-ES_d_ref }}\right)$. A synchronization block is used to transform $V_{\text {series-ES_d_ref }}$ into sinusoidal form ( $\left.\boldsymbol{V}_{\text {series-ES_ref }}\right)$, which is kept in phase or out of phase with the mains voltage.

$$
V_{\text {Series-ES_ref }}=\left(V_{s_{-} r e f}-V_{s d}\right)\left(K_{P 1}+K_{I 1} \frac{1}{S}\right) \cdot \sin (\omega t)
$$

The use of the Series-ES to support and suppress the mains voltage requires the Shunt-ES to control the power flow in the ES-B2B via the regulation of DC voltage. The control loop highlighted in blue color (Fig. 7) is designed for this purpose. The filtered DC voltage is compared with its reference. The error $\left(V_{d c_{-} r e f}-V_{d c}\right)$ is fed to a PI controller to generate $V_{\text {shunt-ES_q_ef }}$ (the $q$ component of Shunt-ES voltage reference), which controls the active current of Shunt-ES. In the proposed control scheme, the ES-B2B only uses its active capacity for voltage regulation. Its reactive capacity is deactivated by setting the reactive current reference of Shunt-ES equal to zero $\left(I_{\text {shunt-ES_q_ref }}=0\right)$. In the control block highlighted in green, the reactive current reference of Shunt-ES ( $\left.I_{\text {shunt-ES_q_ref }}\right)$ is subtracted to $I_{\text {shunt-ES_q }}($ the reactive current of Shunt-ES). The 
TABLE II

SPECIFICATIONS OF THE ES-B2B

\begin{tabular}{cc}
\hline \hline Symbol & Value \\
\hline Power switch & IRFP30N50 \\
$L C L$ filter & $L=500 \mu \mathrm{H}, C=13.2 \mu \mathrm{F}, L_{g}=11 \mathrm{mH}$ \\
$L C$ filter & $L=500 \mu \mathrm{H}, C=13.2 \mu \mathrm{F}$ \\
$D C$ Capacitors & $C_{l}=6 \times 1500 \mu \mathrm{F}, C_{2}=6 \times 1500 \mu \mathrm{F}$ \\
Switching frequency & $30 \mathrm{kHz}$ \\
Regulated $D C$-link voltage & $360 \mathrm{~V}$ \\
Dead band & $20 \mathrm{~ns}$ \\
Series-ES output voltage & $0-80 \mathrm{~V}$ \\
range (RMS) & \\
\hline \hline
\end{tabular}

error is fed to a PI controller to derive $V_{\text {Shunt-ES_d_ref }}$ (the $d$ component of Shunt-ES voltage reference). A synchronization stage is set to align $V_{\text {shunt-ES_d ref }}$ and $V_{\text {shunt-ES_q_ref. }}$ The complete control loop of Shunt-ES is mathematically expressed as

$$
\begin{aligned}
V_{\text {Shunt-ES_ref }}= & {\left[V_{\text {sd }}+\left(I_{\text {Shunt-ES_q_ref }}-I_{\text {Shunt-ES_q }}\right)\left(K_{P 2}+K_{I 2} \frac{1}{S}\right)\right] \cdot \sin (w t) } \\
& +\left[V_{s q}-\left(V_{d c_{-} r e f}-V_{d c}\right)\left(K_{P 3}+K_{I 3} \frac{1}{S}\right)\right] \cdot \cos (w t)
\end{aligned}
$$

\section{HARDWARE IMPLEMENTATION OF ES-B2B}

The practical implementation of the ES-B2B consists of three segments: 1) the power electronic back-to-back converter circuit, 2) a sampling system and data processing stage, and 3) a controller designed for the mains voltage stabilization and DC voltage control of the ES-B2B. The specifications of the hardware of ES-B2B implemented in a $110 \mathrm{~V}$ distribution grid are included in TABLE II.

Both half-bridge inverters in Fig. 3 use N-channel MOSFETs as power switches. Two sets of capacitors with 9000 $\mu \mathrm{F}$ and $250 \mathrm{~V}$ voltage ratings are used to buffer energy for either positive or negative cycle. One half-bridge inverter of the ES-B2B is implemented as series-inverter (Series-ES). Its PWM output voltage is filtered by a LC filter. The output of the Series-ES is a controllable sinusoidal voltage. The other half-bridge inverter is implemented as a shunt inverter (Shunt-ES) which is connected to the mains via an inductor.

The proposed controller is implemented in a dSpace 1104. Voltage and current sensors are used to capture the waveforms of Series-ES and Shunt-ES for control purpose and visualization. The sampling frequency of the controller is set at $10 \mathrm{k} \mathrm{Hz}$. The PWM generator has a switching frequency of 30 $\mathrm{kHz}$ and a dead band of $20 \mathrm{~ns}$. Two digital input ports are used to provide the enable and disable signals for the Series-ES and the Shunt-ES.

\section{EXPERIMENTAL AND SIMULATION RESULTS}

In this section, the function of the ES-B2B to support and suppress the mains voltage is firstly demonstrated by experiments. The coordinated power flow of the Series-ES and Shunt-ES is practically evaluated. After verifying the functions of the ES-B2B experimentally, a circuit model is developed and
TABLE III

SPECIFICATIONS OF POWER SYSTEM WITH ES-B2B

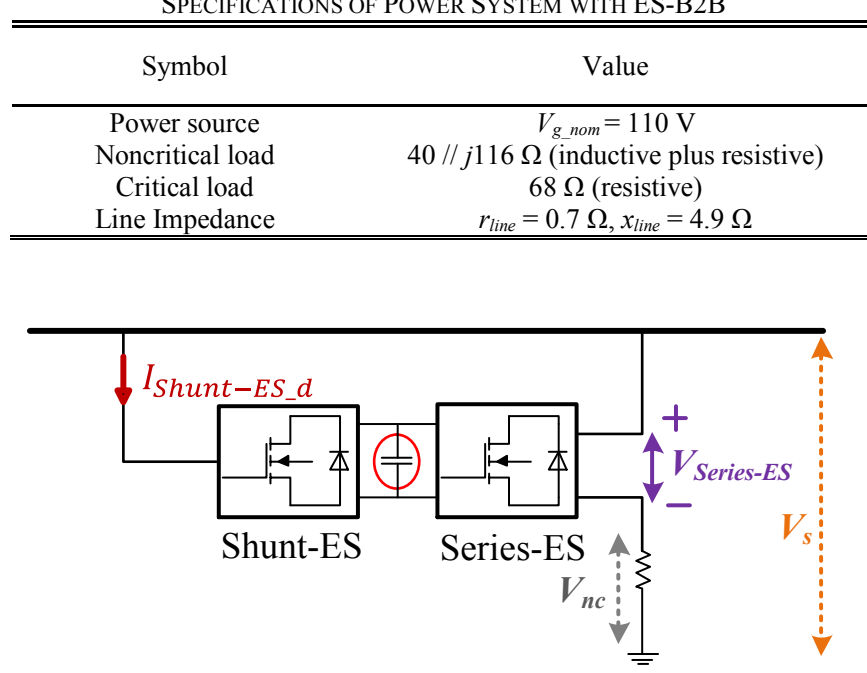

Fig. 8. Notations of measured variables of ES-B2B.

used in a power simulation study. The hardware setup is based on the schematic in Fig. 3. A programmable power supply is used to emulate the power source. The nominal mains voltage is assumed to be $110 \mathrm{~V}$. The programmable power supply is set at a voltage lower than $110 \mathrm{~V}$ in the voltage support tests and higher than $110 \mathrm{~V}$ for the voltage suppression tests. TABLE III gives the specifications of the hardware setup.

\section{A. Practical Tests on the use of ES-B2B for Voltage Support}

The first experiment is conducted to demonstrate the use of the ES-B2B to support the mains voltage. The notations of the measured variables are shown in Fig. 8. The power source is programmed to generate a voltage across the ciritcal load at about $105 \mathrm{~V}$ (i.e. $5 \mathrm{~V}$ lower than the nominal value of $110 \mathrm{~V}$ ). The ES-B2B is operated (i) with Shunt-ES maintaining a stable DC voltage and Series-ES bypassed and (ii) with the Series-ES activated after the first $60 \mathrm{~s}$. The measured mains voltage and the Series-ES voltage are shown in Fig. 9. It can be seen that at $t=60 \mathrm{~s}$, the Series-ES is activated and the mains voltage is restored to $110 \mathrm{~V}$. The voltage support function of the ES-B2B is practically confirmed.

To hightligh the effectivness of ES-B2B in supporting the mains voltage, the measurement of the ES-1 working for the same function is shown in Fig. 10. After the ES-1 is activated at $t=60 \mathrm{~s}$, the mains votlage is restored to about $110 \mathrm{~V}$ as expected. Therefore, both ES-B2B and ES-1 are capable of supporting the mains voltage. But the ES-B2B can react faster than the ES-1 and use less voltage capacity than ES-1 in accomplishing similar compensation results.

Other measurements of the ES-B2B under the voltage support mode are included in Fig. 11 to Fig. 13. In the first $60 \mathrm{~s}$ of Fig. 11, the Shunt-ES consumes a small amount of active current $\left(I_{\text {Shunt-ES_d }}\right)$ to compensate for the circuit loss in order to maintain a stable DC voltage. The current consumed by the noncritical load does not participate in compensation. At $t=60$ $\mathrm{s}$, the Series-ES is activated to support the mains voltage. The compensation voltage ( $V_{\text {series-ES }}$ or the lower trace of Fig. 9$)$ is in phase with the mains voltage and reduces the power of the noncritical load. As a result, the active and reactive current of 


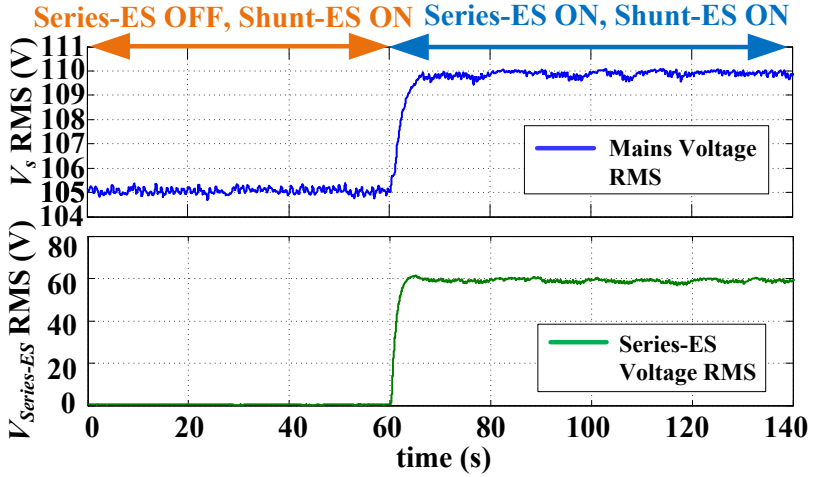

Fig. 9. Experimental mains voltage (upper trace) and the voltage of the Series-ES (lower trace) in voltage support mode.

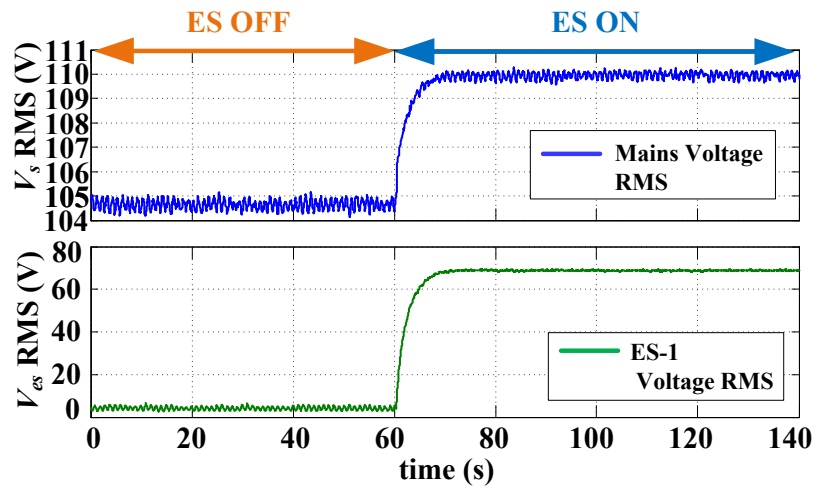

Fig. 10. Experimental mains voltage (upper trace) and the voltage of the ES-1 (lower trace) in voltage support mode. [For comparison with the results in Fig.9.]

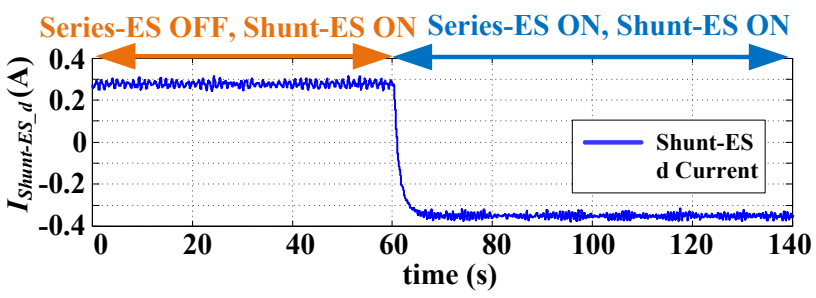

Fig. 11. Experimental active current of the Shunt-ES in voltage support mode.

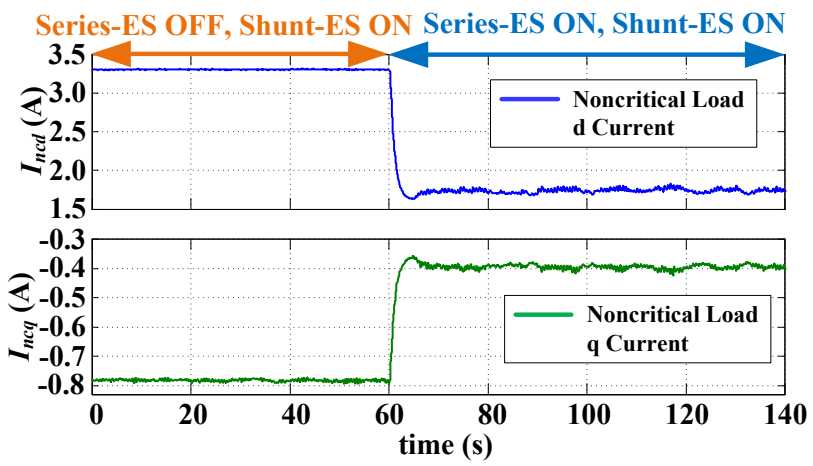

Fig. 12. Experimental active current $\left(I_{n c d}\right)$ and reactive $\left(I_{n c q}\right)$ current of the noncritical load in voltage support mode.

the noncritcal load ( $I_{n c d}$ and $I_{n c q}$ in Fig. 12) are reduced after $t=$ $60 \mathrm{~s}$. The Shunt-ES is adjusted to cooperate with the Series-ES. Since the Series-ES operates in resistive mode to support the mains voltage, the absorbed power is delivered to the DC link

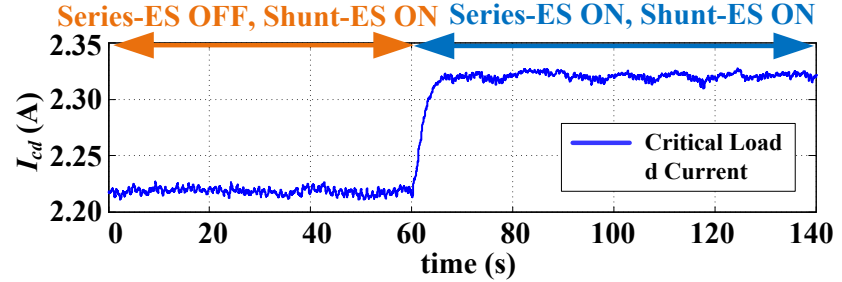

Fig. 13. Experimental active current of the critical load in voltage support mode.

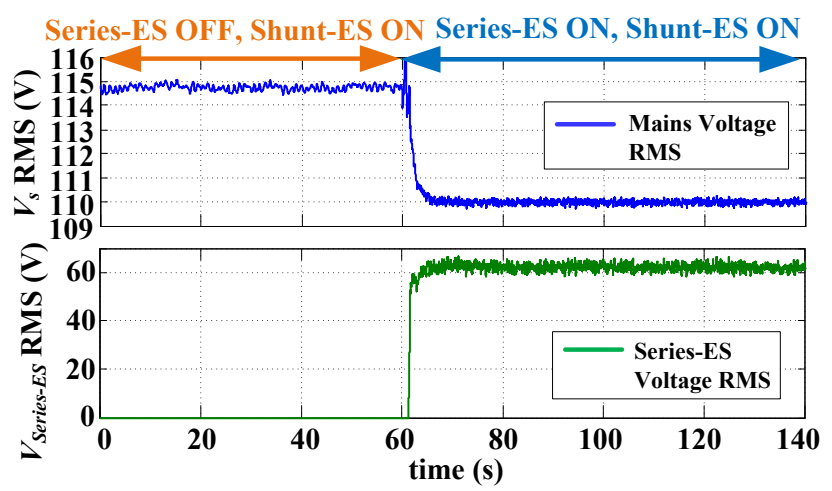

Fig. 14. Experimental mains voltage (upper trace) and the voltage of the Series-ES (lower trace) in voltage suppression mode.
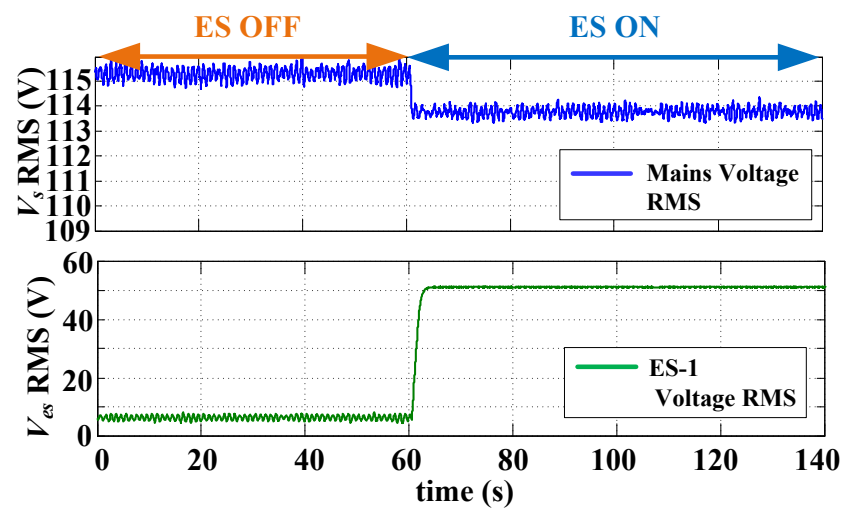

Fig. 15. Experimental mains voltage (upper trace) and the voltage of the ES-1 (lower trace) in voltage suppression mode. [For comparison with the results in Fig.14.]

and circulated through the Shunt-ES back to the mains. This is evidenced by the reverse of the $I_{\text {Shunt-ES } d}$ from positive to negative in Fig. 11. In Fig. 9, the voltage bouncing effect of the Series-ES restores the mains votlage to $110 \mathrm{~V}$ after $t=60 \mathrm{~s}$. The supported voltage causes the active current of the critical load $\left(I_{c d}\right)$ to increase as shown in Fig. 13.

\section{B. Practical Tests on the use of ES-B2B for Voltage Suppression}

The second set of experiment was conducted to evaluate the voltage suppression function of the ES-B2B. The programmable power supply was set at $115 \mathrm{~V}$ (i.e. $5 \mathrm{~V}$ higher than the nominal value). The difference between the performance of the ES-B2B and the original ES-1 can be clearly observed as addressed in the following discussion.

The ES-B2B is initiated with its Shunt-ES in action for providing a regulated dc link voltage and its Series-ES kept in an idle state. The Series-ES is turned on at $t=60 \mathrm{~s}$. The 


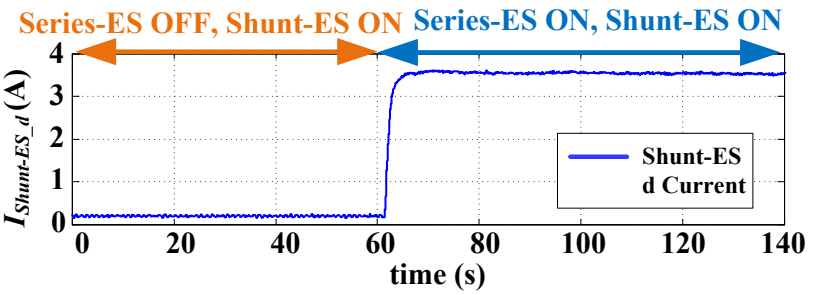

Fig. 16. Experimental active current of the Shunt-ES in voltage suppression mode.

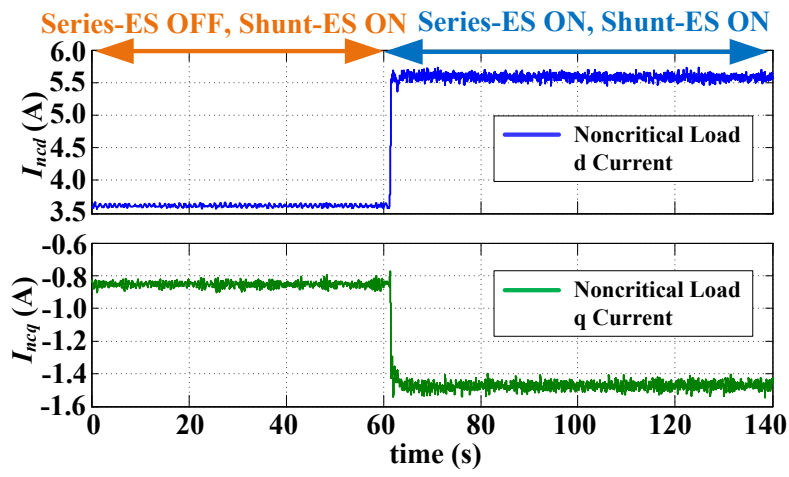

Fig. 17. Experimental active current $\left(I_{n c d}\right)$ and reactive current $\left(I_{n c q}\right)$ of the noncritical load in voltage suppression mode.

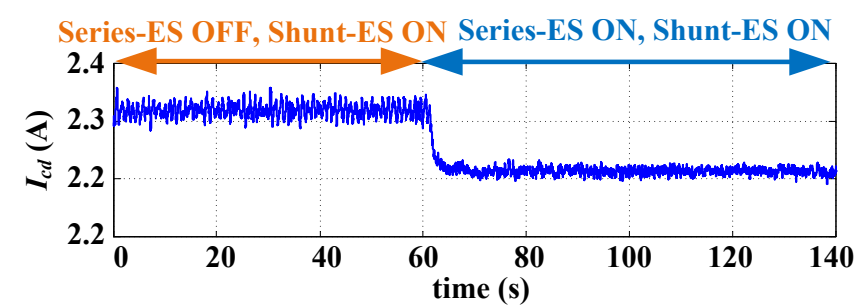

Fig. 18. Experimental active current of the critical load in voltage suppression mode.

measured mains voltage and the voltage of the Series-ES are shown in Fig. 14. It can be seen that the ES-B2B can effectively suppress the mains voltage from $115 \mathrm{~V}$ to $110 \mathrm{~V}$. For the same test conditions with the use of ES-1, a set of waveforms are included in Fig. 15. Comparing the upper traces of Fig. 14, Fig. 15 indicates that ES-1 is not as effective as the ES-B2B in suppressing the mains voltage. The main reason is that the ES-1 does not have direct control of active power as the ES-B2B does. The ES-B2B does not have the limitation that the phasor relationship between noncritical load current and the series compensation voltage is restricted to $90^{\circ}$ or $270^{\circ}$.

Other experimental results of the ES-B2B are included in Fig. 16 to Fig. 18. Fig. 16 shows that the Shunt-ES of the ES-B2B provides a small active current $\left(I_{\text {Shunt-ES } d \text { d }}\right)$ to cover the circuit power loss in the first $60 \mathrm{~s}$ (when the Series-ES is not activated yet). At $t=60 \mathrm{~s}$, the Series-ES is activated to suppress the mains voltage. As indicated by Fig. 14, the Series-ES generates a compensation voltage out of phase with the mains voltage. This compensation voltage increases the noncritical load voltage. The active and reactive current of the noncritical load ( $I_{n c d}$ and $\left.I_{n c q}\right)$ in Fig. 17 shows that the power of the noncritical load is increased in order to reduce the mains voltage. Meanwhile, the Shunt-ES increases its active current (Fig. 16). Since the mains

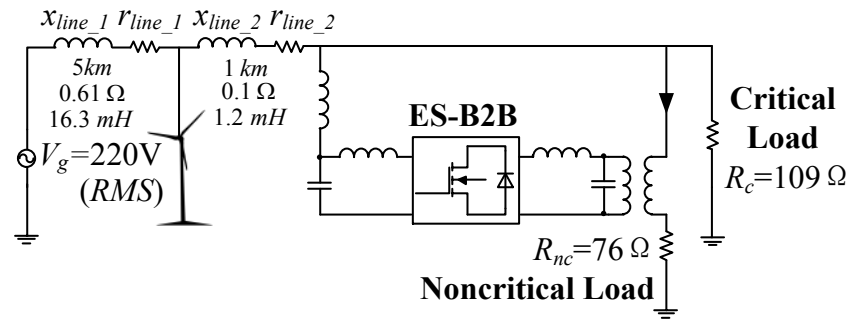

Fig. 19. The configuration of a weak grid.

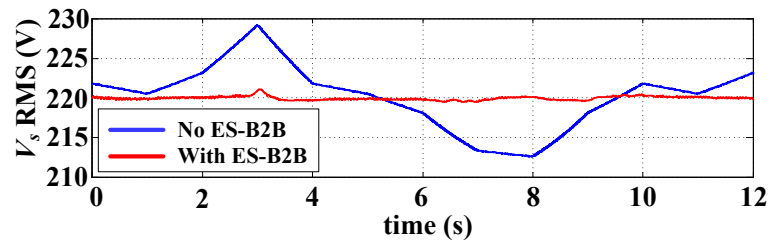

Fig. 20. Simulated mains voltage with and without ES-B2B.

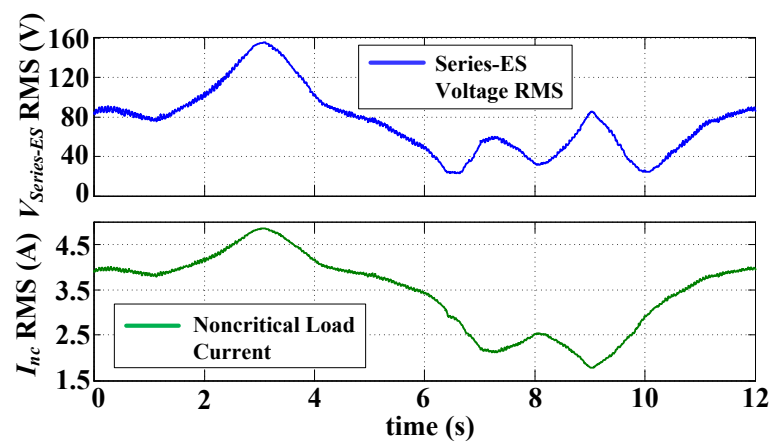

Fig. 21. Simulated voltage of Series-ES (upper trace) and the current of noncritical load (lower trace).

voltage is restored from $115 \mathrm{~V}$ to $110 \mathrm{~V}$, the active current of the critical load is reduced after $t=60 \mathrm{~s}$ as shown in Fig. 18.

\section{Operation of the ES-B2B in a Weak Grid (Simulation Study)}

In this section, a simulation study has been conducted to examine the voltage regulation function of ES-B2B in a weak power grid with large penetration of intermittent renewable energy sources. The configuration and specifications are given in Fig. 19. The renewable energy source is modeled as a current source that generates fluctuating current into the grid. The ES-B2B is implemented to smooth the voltage fluctuation. The Series-ES is connected in series with a noncritical load via an isolation transformer. The Shunt-ES is attached to the mains via an inductor. A critical load of resistive type is connected to the mains. The circuit model of the weak grid and the ES-B2B is developed in MATLAB/SIMULINK. The model of ES-B2B has a higher voltage rating and thus can be implemented in a typical distribution system with a nominal mains voltage of 220 $\mathrm{V}$ (RMS). The DC voltage of ES-B2B is set at $660 \mathrm{~V}$. The voltage of Series-ES is limited to $160 \mathrm{~V}$ (RMS).

The simulated mains voltage with and without ES-B2B are shown in Fig. 20. These results indicate that the ES-B2B can effectively mitigate the voltage fluctuation caused by the intermittent renewable power generation. The results in Fig. 21 show that the Series-ES of the ES-B2B actively changes the supply voltage of the noncritical load by generating an 


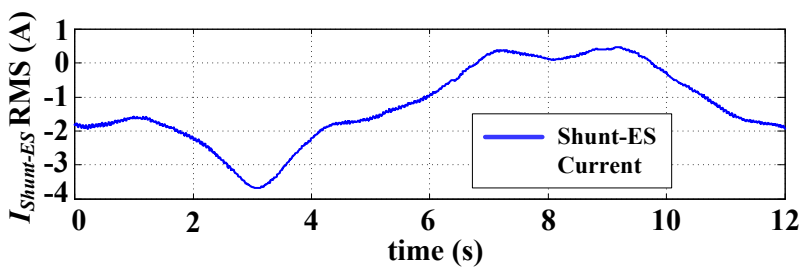

Fig. 22. Simulated current of the Shunt-ES.

adjustable compensation voltage. The active current of the Shunt-ES shown in Fig. 22 indicates that the Shunt-ES can absorb or inject active power to keep a balanced power flow of ES-B2B and a stable DC link voltage.

\section{CONCLUSIONS}

This paper reports the first hardware implementation and control of a back-to-back electric spring (ES-B2B). Unlike the previous versions that is based on an inverter fed by a capacitor (ES-1) or a battery (ES-2), this version of electric spring is based on a back-to-back converter topology. This ES-B2B has the advantage over ES-1 by providing highly effective voltage support and suppression functions, while the ES-1 is less effective in voltage suppression. The proposed topology and control have been practically confirmed. The experimental results have verified the high performance of the ES-B2B for the regulation of the mains voltage. The simulation study of a weak power grid also indicates the usefulness of the ES-B2B in dynamically mitigating voltage fluctuation caused by intermittent renewable power generation.

\section{ACKNOWLEDGEMENT}

The authors are grateful to the Hong Kong Research Grant Council for its support of the Theme-based Research Project (T23-701/14-N).

\section{REFERENCES}

[1] P. P. Varaiya, F. F. Wu, and J. W. Bialek, "Smart Operation of Smart Grid: Risk-Limiting Dispatch," Proc. IEEE, vol. 99, no. 1, pp. 40-57, Jan. 2011.

[2] I. Koutsopoulos and L. Tassiulas, "Challenges in demand load control for the smart grid," IEEE Network, vol. 25 , no. 5, pp. 16-21, Oct. 2011.

[3] A. Mohsenian-Rad, V. W. S. Wong, J. Jatskevich, R. Schober, and A. Leon-Garcia, "Autonomous demand-side management based on game-theoretic energy consumption scheduling for the future smart grid," IEEE Trans. Smart Grid, vol. 1, no. 3, pp. 320-331, Dec. 2010.

[4] M. Parvania and M. Fotuhi-Firuzabad, "Demand response scheduling by stochastic SCUC," IEEE Trans. on Smart Grid, vol. 1, no. 1, pp. 89-98, Jun. 2010.

[5] M. Pedrasa, T. D. Spooner and I. F. MacGill, "Scheduling of demand side resources using binary particle swarm optimization," IEEE Trans. Power Systems, vol. 24, no. 3, pp. 1173-1181, Aug. 2009.

[6] F. Kienzle, P. Ahein, and G. Andersson, "Valuing investments in multi-energy conversion, storage, and demand-Side management systems under uncertainty," IEEE Trans Sustain. Energy, vol. 2, no. 2, pp. 194202, Apr. 2011.

[7] A. J. Conejo, J. M. Morales, and L. Baringo, "Real-time demand response model," IEEE Trans. Smart Grid, vol. 1, no. 3, pp. 236-242, Dec. 2010.

[8] A. H. Mohsenian-Rad and A. Leon-Garcia, "Optimal residential load control with price prediction in real-time electricity pricing environments," IEEE Trans. Smart Grid, vol. 1, no. 2, pp. 120-133, Sep. 2010.

[9] A. J. Roscoe and G. Ault, "Supporting high penetrations of renewable generation via implementation of real-time electricity pricing and demand response," IET Renewable Power Gener., vol. 4, no. 4, pp. 369-382, Jun. 2010.

[10] S. Y. R. Hui, C. K. Lee, and F. F. Wu, "Electric springs-a new smart grid technology," IEEE Trans. Smart Grid, vol. 3, no. 3, pp. 1552-1561, Sep. 2012.

[11] C. K. Lee, B. Chaudhuri, and S. Y. Hui, "Hardware and control implementation of electric springs for stabilizing future smart grid with intermittent renewable energy sources," IEEE J. Emerg. Sel. Topics Power Electron., vol. 1, no. 1, pp. 18-27, Mar. 2013.

[12] Z. Akhtar, B. Chaudhuri, and S.Y.R. Hui, "Primary frequency control contribution through smart loads using reactive compensation," IEEE Trans. Smart Grid, vol. 6, no. 5, pp. 2356-2365, Sep. 2015.

[13] Q. Wang, M. Cheng, Z. Zhen, and Z. Wang, "Steady-state analysis of electric springs with a novel $\delta$ control," IEEE Trans. Power Electro., vol. 30, no. 12, pp. 7159-7169, Dec. 2015.

[14] Lee C.K. and Hui S.Y.R., "Reduction of energy storage requirements for smart grid using electric springs," IEEE Trans. Smart Grid, vol. 4, no. 3, pp. 1282-1288, Sep. 2013.

[15] S. Yan, S. C. Tan, C. K. Lee, B. Chaudhuri, and R. Y. Ron Hui, "Electric springs for reducing power imbalance in three-phase power systems," IEEE Trans. Power Electron., vol. 30, no. 7, pp. 3601-3609, Aug. 2015.

[16] K. R. Krishnanand, S. M. F. Hasani, J. Soni, and S. K. Panda, "Neutral current mitigation using controlled electric springs connected to microgrids within built environment," in Proc. IEEE Energy Convers. Congr. Expo., 2014, pp. 2947-2951.

[17] S. C. Tan, C. K. Lee, and S. Y. R. Hui, "General steady-state analysis and control principle of electric springs with active and reactive power compensations," IEEE Trans. Power Electron., vol. 28, no. 8, pp. 39583969, Aug. 2013.

[18] S. Yan, S. C. Tan, C. K. Lee, and S. Y. R. Hui, "Electric spring for power quality improvement," in Proc. IEEE Appl. Power Electron. Conf. Expo., 2014, pp. 2140-2147.

[19] Z. Akhtar, B. Chaudhuri, and S. Y. R. Hui, "Smart loads for voltage control in distribution networks," IEEE Trans. on Smart Grid, (Early Access).

[20] K. T. Mok, S. C. Tan, and S. Y. R. Hui, "Decouple power angle and voltage control of electric springs," IEEE Trans. Power Electron., vol. 31, no. 2, pp. 1216-1229, Feb. 2016.

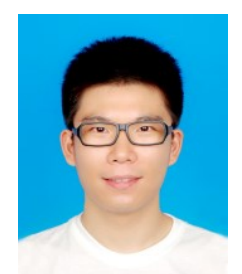

Yan Shuo (S'13) received the B. Eng. in electrical engineering from South China University in 2007, and M. Phil in electrical engineering from Southeast University in 2010 . He is currently working toward the $\mathrm{Ph}$. D. in electrical engineering at the department of electrical and electronic engineering, The University of Hong Kong.

His current research interests include power electronic technology in smart grid, advance control of renewable energy sources, and Microgrid.

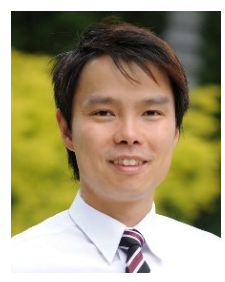

Chi Kwan Lee (M'08-SM'14) received the B.Eng. and $\mathrm{Ph} . \mathrm{D}$. degrees in electronic engineering from the City University of Hong Kong, Kowloon, Hong Kong, in 1999 and 2004, respectively.

$\mathrm{He}$ is currently an Assistant Professor at the Department of Electrical \& Electronic Engineering, The University of Hong Kong. Since 2010, He has been a Visiting Researcher with Imperial College London.

Dr. Lee was a Postdoctoral Research Fellow in the Power and Energy Research Centre at the National University of Ireland, Galway, from 2004 to 2005. In 2006, he joined the Centre of Power Electronics in City University of Hong Kong as a Research Fellow. In 2008-2011 he was a Lecturer of Electrical Engineering at the Hong Kong Polytechnic University. He won an IEEE Power Electronics Transactions First Prize Paper Award for his publications on Mid-Range Wireless Power Transfer in 2015. He is a co-inventor of the Electric Springs and planar EMI filter. His current research interests include wireless power transfer, clean energy technologies, and smart grids. 


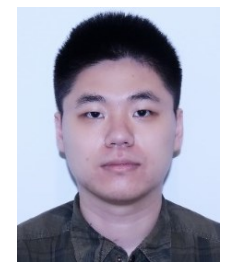

Tianbo Yang (S'15) received the B.Eng. and M.Phil. degrees in automation and control engineering from the Harbin Institute of Technology, China, in 2012 and 2014, respectively. He is currently pursuing the Ph.D. degree at the Department of Electrical and Electronic Engineering, the University of Hong Kong. His research interest includes power electronic technologies in smart grid and energy storage system.

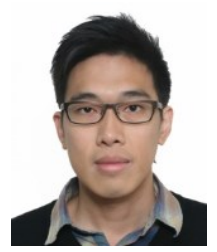

Kwan-Tat Mok (S'14) received the B.Eng. (Hons.) and M.Phil. degrees in electronic and information engineering from the Hong Kong Polytechnic University, in 2009 and 2012, respectively. In 2007, he worked as an Engineering Trainee in Solomon Systech Limited, Hong Kong, for a one-year internship program. From September 2011 to February 2013, he was an Embedded System Engineer in Cwlinux Limited, Hong Kong. From July to August 2015, he was a visiting postgraduate student in Department of Electrical and Electronic Engineering, Imperial College London. He is currently a Ph.D. candidate in Power Electronics Research Group, Department of Electrical and Electronic Engineering, The University of Hong Kong. His research interests include smart grid technologies, electric springs and power converters for light-emitting diodes.

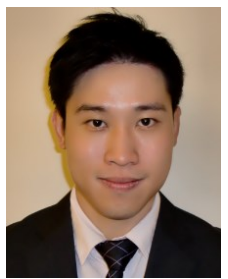

Siew-Chong Tan (M'06-SM'11) received the B.Eng. (Hons.) and M.Eng. degrees in electrical and computer engineering from the National University of Singapore, Singapore, in 2000 and 2002, respectively, and the $\mathrm{Ph} . \mathrm{D}$. degree in electronic and information engineering from the Hong Kong Polytechnic University, Hong Kong, in 2005.

From October 2005 to May 2012, he worked as Research Associate, Postdoctoral Fellow, Lecturer, and Assistant Professor in Department of Electronic and Information Engineering, Hong Kong Polytechnic University, Hong Kong. From January to October 2011, he was Senior Scientist in Agency for Science, Technology and Research (A*Star), Singapore. He is currently an Associate Professor in Department of Electrical and Electronic Engineering, The University of Hong Kong, Hong Kong. Dr. Tan was a Visiting Scholar at Grainger Center for Electric Machinery and Electromechanics, University of Illinois at Urbana-Champaign, Champaign, from September to October 2009, and an Invited Academic Visitor of Huazhong University of Science and Technology, Wuhan, China, in December 2011. His research interests are focused in the areas of power electronics and control, LED lightings, smart grids, and clean energy technologies.

Dr. Tan serves extensively as a reviewer for various IEEE/IET transactions and journals on power, electronics, circuits, and control engineering. He is an Associate Editor of the IEEE Transactions on Power Electronics. He is a coauthor of the book Sliding Mode Control of Switching Power Converters: Techniques and Implementation (Boca Raton: CRC, 2011).

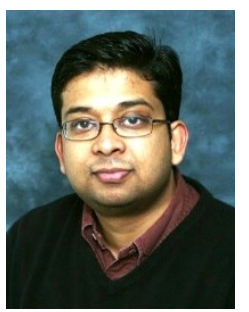

Balarko Chaudhuri (M'06-SM'11) received the $\mathrm{Ph} . \mathrm{D}$. degree in Electrical and Electronic engineering from Imperial College London, London, U.K., in 2005 where he is currently a Senior Lecturer at the Control and Power Research Group. His research interests include power systems stability, grid integration of renewables, HVDC, FACTS, demand response and smart grids. Dr. Chaudhuri is an editor of the IEEE Transactions on Smart Grid and an associate editor of the IEEE Systems Journal and Elsevier Control Engineering Practice. He is a Fellow of the Institution of Engineering and Technology (IET) and a member of the International Council on Large Electric Systems (CIGRE).

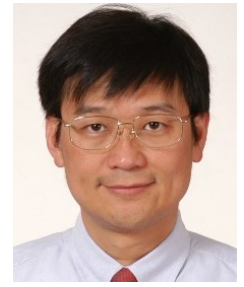

S. Y. (Ron) Hui (M'87-SM'94-F'03) received his BSc (Eng) Hons at the University of Birmingham in 1984 and a D.I.C. and $\mathrm{PhD}$ at Imperial College London in 1987. Presently, he holds the Philip Wong Wilson Wong Chair Professorship at the University of Hong Kong and a part-time Chair Professorship at Imperial College London.

$\mathrm{He}$ has published over 300 technical papers, including more than 220 refereed journal publications. Over 60 of his patents have been adopted by industry. He is an Associate Editor of the IEEE Transactions on Power Electronics and IEEE Transactions on Industrial Electronics, and an Editor of the IEEE Journal of Emerging and Selected Topics in Power Electronics. His inventions on wireless charging platform technology underpin key dimensions of Qi, the world's first wireless power standard, with freedom of positioning and localized charging features for wireless charging of consumer electronics. He received the IEEE Rudolf Chope R\&D Award from the IEEE Industrial Electronics Society and the IET Achievement Medal (The Crompton Medal) in 2010, and IEEE William E. Newell Power Electronics Award in 2015. He is a Fellow of the Australian Academy of Technological Sciences \& Engineering and also the Royal Academy of Engineering, U.K. 